\title{
Resonant Converter with Fully-Compensated Isolation Transformer
}

\author{
Joon Heo, Seong-Jeub Jeon \\ Dept. of Electronic Engineering, Pukyong National University \\ Daeyon 3-Dong, Nam-Gu, Busan, Korea \\ hj10000@hanmail.net; jeub@pknu.ac.kr
}

\begin{abstract}
In this paper, a resonant converter with a fully-compensated isolation transformer is proposed. An isolation transformer is equipped for the safety of users, and its leakage inductances are used for resonance in a conventional design. In the present proposal, the total self-inductances are used for resonances. When a transformer is fully compensated, its primary voltage is proportional to the secondary current and its secondary voltage to the primary current. This property is useful in a wireless power transfer system, where a constant feeder current is preferable. A constant secondary current is obtained with a constant output voltage of a resonant converter. The proposed resonant converter is applied to a wireless charging system for an electric yard tractor. A prototype charging system of 60 $\mathrm{kW}$ is made and tested, and its experimental results are shown.
\end{abstract}

Keywords: Resonant converter, Full compensation, Wireless power transfer, Wireless charging, SiC device

\section{Introduction}

Recently, wireless power transfer is widespread. Low power systems are in home or office appliances [1]-[6] and in mobile/wearable devices [7]-[10]; High power systems are in wireless chargers for electric vehicles [11]-[14]. It provides electric vehicles with a safe and convenient charging medium. Wireless charging is accomplished by a feeder coil and a pickup coil, whose sizes are inversely proportional to the operation frequency. With high frequency operation, inductances lower power transfer capabilities of wireless power transfer systems. Power transfer capabilities can be recovered by compensating with capacitors which constitute resonance circuits with inductors. Power converter supplying power becomes resonant type. To achieve high efficiency with IGBT devices, soft-switching should be adopted. If we use soft switching, usable control scheme of power converter will be limited. Recently, SiC (Silicon Carbide) FETs (Field Effect Transistors) are commercialized. It can operate at up to $100 \mathrm{kHz}$ under hard switching condition because it does not show reverse recovery phenomena. Considering regulations such as ICNIRP (International Commission on Non-Ionizing Radiation Protection) [15], below $100 \mathrm{kHz}$ operation for high power wireless charging system is promising. In this paper, a wireless charging system for electric yard tractor (YT) which is made based on SiC devices and operates at $60 \mathrm{kHz}$ under hard switching condition is studied. In Korea, 20 and $60 \mathrm{kHz}$ frequencies are assigned for use in wireless power charging. The previous operating frequency of KAIST (Korea Advanced Institute of Science and Technology) OLEVs (On-line electric vehicles) was $20 \mathrm{kHz}$ [11]. Performance will be tripled approximately when the frequency is tripled. In this paper, $\mathrm{SiC}$ devices, full-compensation scheme and its control scheme are adopted to a resonant converter for wireless charging of electric YTs.

\section{Wireless Charging System for Electric YT}

Fig. 1(a) shows an electric YT with wireless charging system. The electric YT is equipped with traction inverter, traction motor and battery. For wireless power charging, a pickup and a regulator for battery charging are mounted additionally. Fig. 1(b) shows block diagram of a wireless charging system for YT. At stationary station, high frequency inverter supplies power to a feeder coil. Power is transferred from a feeder coil to a pickup coil without electric contact. Sizes of feeder coils and pickup coils can be reduced with high frequency operation. To reduce switching loss of a power converter caused by high frequency operation, resonant converters are adopted. In this paper, a resonant converter with a fully-compensated isolation transformer for wireless charging is proposed. In a conventional resonant converter, leakage inductances are used for resonances, however, in this proposal total self-inductances are used for resonances. 


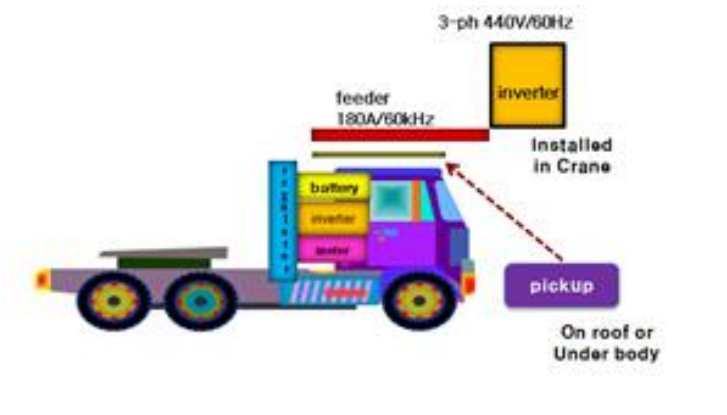

(a)

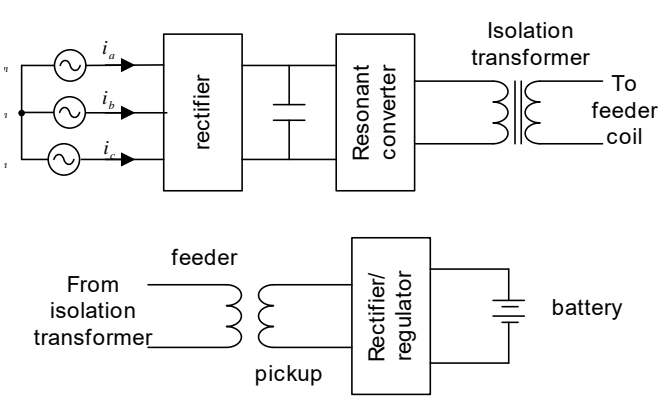

(b)

Fig. 1: Yard tractor with wireless charging system, (a): Electric Yard tractor, (b) Charging System.

\section{Resonant Converter with Fully Compensated Isolation Transformer}

Two kinds of equivalent circuits for the isolation transformer are shown in Fig. 2, where winding resistances are ignored. One is based on an ideal transformer, and the other on a coupled inductor. In a usual resonant converter, resonances are made to cancel the leakage inductances $L_{l 1}$ and $L_{l 2}$ of the isolation transformer shown in Fig. 2(a). The magnetizing inductance $L_{m}$ is considered big and ignored. In this paper, resonances are made to cancel full self-inductances [11], [12]. The self-inductance $L_{1}$ in Fig. 2(b) corresponds to $L_{l 1}+L_{m}$ in Fig. 2(a). There is a big merit in a resonant converter with fully compensated isolation transformer. The primary current is proportional to the secondary induced voltage, and the primary induced voltage proportional to the secondary current. Assuming sinusoidal operation, the voltage-current relationship is given as follows using phasors:

$$
\begin{aligned}
\mathbf{V}_{1} & =\frac{1}{j \omega C_{r 1}} \mathbf{I}_{1}+j \omega L_{1} \mathbf{I}_{1}-j \omega M_{T} \mathbf{I}_{2} \\
\mathbf{V}_{2} & =j \omega M_{T} \mathbf{I}_{1}-j \omega L_{2} \mathbf{I}_{2}-\frac{1}{j \omega C_{r 2}} \mathbf{I}_{2}
\end{aligned}
$$

where $L_{1}$ and $L_{2}$ are self-inductances of the primary and the secondary sides, respectively. $C_{\mathrm{r} 1}$ and $C_{\mathrm{r} 2}$ are resonance capacitors of the primary and the secondary sides, respectively. In this proposal, full compensation is adopted. Full compensation conditions are as follows:

$$
\begin{aligned}
& \frac{1}{\omega C_{r 1}}=\omega L_{1}, \\
& \frac{1}{\omega C_{r 2}}=\omega L_{2} .
\end{aligned}
$$

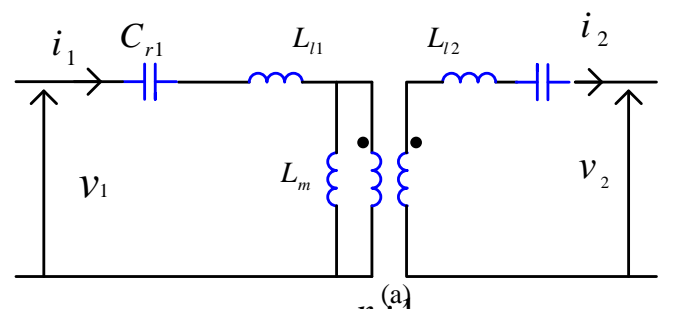

Fig. 2: Equivalent circuits of isolation transformer with resonance capacitors

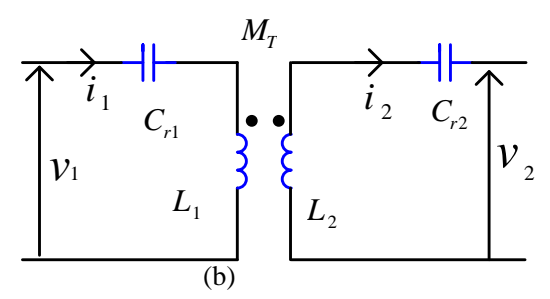

(a) model based on ideal transformer, (b) coupled inductor model. 
Contrary to usual resonant converters, constant frequency operation is adopted in this proposal [16]. Hence full compensation is maintained constantly. Eqs. (1) and (2) are expressed under full compensation condition, as follows:

$$
\begin{aligned}
& \mathbf{V}_{1}=-j \omega M_{T} \mathbf{I}_{2} \\
& \mathbf{V}_{2}=j \omega M_{T} \mathbf{I}_{1}
\end{aligned}
$$

The isolation transformer is expressed as two current-controlled voltage sources as in Fig. 3. In the conventional design, the primary current is proportional to the secondary current of the isolation transformer. However, in this present design, the primary voltage and the secondary current are proportional to each other. When we want constant secondary current, it can be obtained by applying constant voltage to the primary side of the isolation transformer. The voltage is controlled by PWM (Pulse Width Modulation). When PWM is adopted, soft switching is not guaranteed. However, in this proposal, SiC FETs are selected for switching devices. Si based power devices such as IGBTs suffer reverse recovery as shown Fig. 4 when operate under hard switching condition. Reverse recovery time, $t_{\text {rr }}$ shown in Fig 4, is the time needed for a diode or an anti-paralleled diode of IGBT to regain reverse blocking capability [17]. Switching loss is greatly increased and their operating frequency is limited when they suffer reverse recovery. Usually, $20 \mathrm{kHz}$ is the maximum switching frequency when they are operating under hard switching condition. However, SiC devices do not suffer reverse recoveries. Accordingly their maximum frequency is much higher than IGBTs. SiC FETs can operate at up to $100 \mathrm{kHz}$ under hard switching condition. SiC FET enables us to choose power circuits with simple topology and control. The operation frequency of $60 \mathrm{kHz}$ is selected because 20 and $60 \mathrm{kHz}$ are assigned for this kind of high power wireless charging equipment in Korea and a better performance can be achievable with higher frequency. When load draws power, induced voltage by load current is inserted in the feeder loop, and the primary current increases according to (5). The primary current is proportional to the secondary voltage of the isolation transformer.

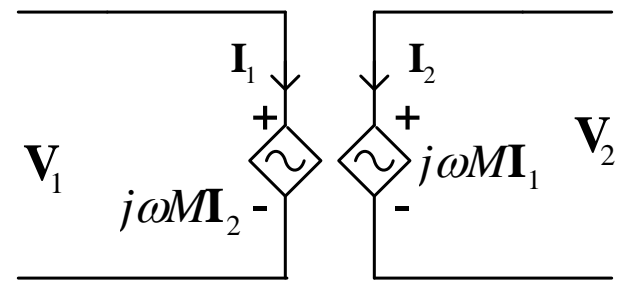

Fig. 3: Equivalent circuit after full compensation.

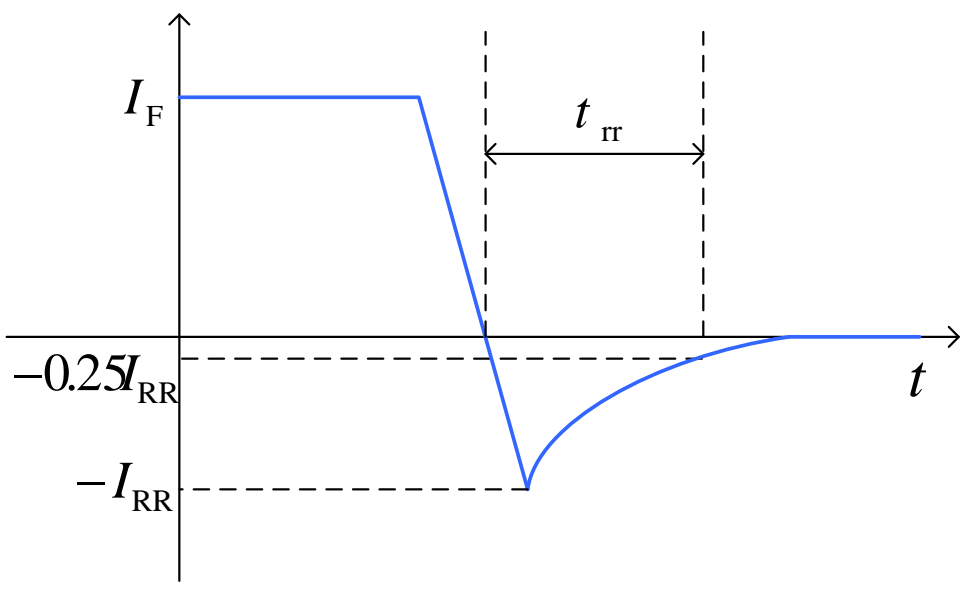

Fig. 4: Reverse recovery phenomenon. 


\section{Experimental Results}

A $60 \mathrm{~kW}$ prototype resonant converter is made for validation of the proposal. The circuit parameters of the prototype are shown in Table I. The high frequency inverter is constructed with SiC FET CAS300M12BM2 from Cree. Its rated voltage and current are $1200 \mathrm{~V}$ and 300 A, respectively. Combination of Celem's CT500 and CSP 150/200 capacitors are used to satisfy the required resonance capacitances. As now, experiments are progressing. Partial experimental results are shown in Figs. 5, 6, 7 and 8. Fig. 5 shows the waveforms when the primary side circuit is shorted. A short circuit at the primary side of the isolation transformer is made due to the primary-side resonance by opening feeder side i.e. the secondary side of the isolation transformer. The output voltage of the resonant inverter is adjusted so that the rated current $\left(180 \mathrm{~A}_{\mathrm{rms}}\right)$ is flowing through power devices and the primary side of the isolation transformer. It is assured that the primary winding of the isolation transformer and the resonant converter are working properly at their rated current. The output voltage of the resonant converter is very small due to the short circuit made with full resonance. Fig. 6 shows relationship between the induced voltage at the secondary side of the isolation transformer and the primary current. Linearity is well maintained. Fig. 7 shows operation waveforms under no load condition at primary side. No load condition is made by closing feeder circuit but opening pickup side. The rated current $\left(180 \mathrm{~A}_{\mathrm{rms}}\right)$ is flowing through the feeder circuit including the secondary side of the isolation transformer. It is assured that the secondary winding of the isolation transformer and the feeder circuit are working properly at rated current. From these two experiments it is verified that the fully-compensated transformer is well-designed and working according to the proposal and the analysis. For loading test, loading-back method is used. The output power is returned to the resonant converter via a two-phase Buck converter. Fig. 8 shows load test waveforms. The pickup voltage is measured just before rectifier. The output power of the pickup after rectification is about $40 \mathrm{~kW}$. We are raising output power, and will increase up to $60 \mathrm{~kW}$ before conference date.

Table 1: Circuit Components and Parameters.

\begin{tabular}{|c|c|c|c|c|c|c|}
\hline$M_{\mathrm{T}}(\mu \mathrm{H})$ & $L_{1}(\mu \mathrm{H})$ & $L_{2}(\mu \mathrm{H})$ & $L_{\text {feeder }}(\mu \mathrm{H})$ & $C_{\mathrm{r} 1}(\mu \mathrm{F})$ & $C_{\mathrm{r} 2}(\mu \mathrm{F})$ & $L_{\mathrm{pk}}(\mu \mathrm{H})$ \\
\hline 4.2 & 9.65 & 8.08 & 13.8 & 1.03 & 0.472 & 18.1 \\
\hline
\end{tabular}

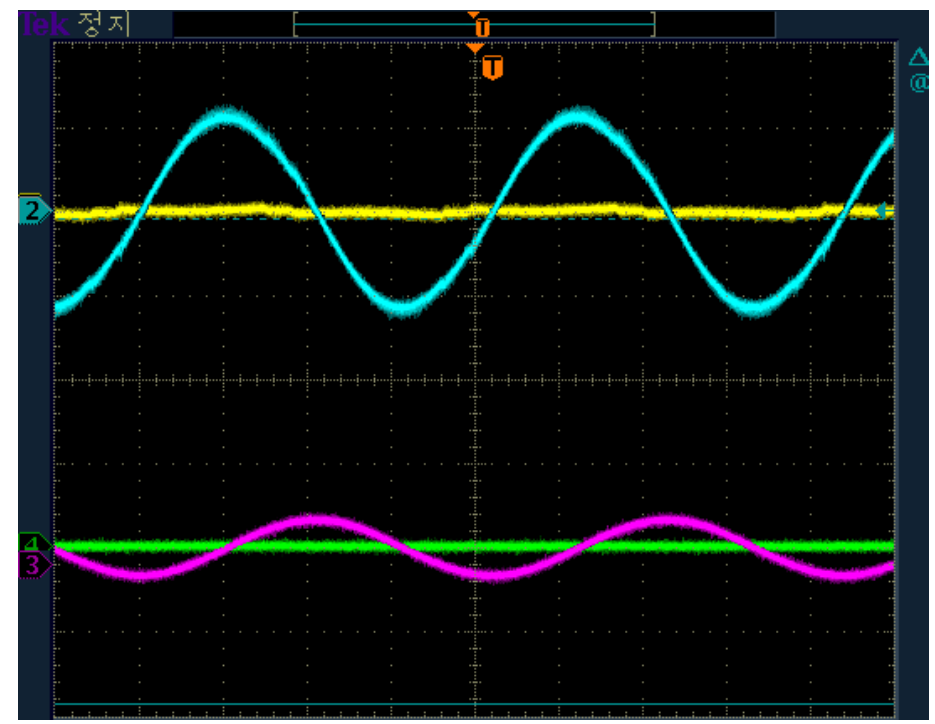

(a) $I_{2}=50 \mathrm{~A}_{\mathrm{rms}}$

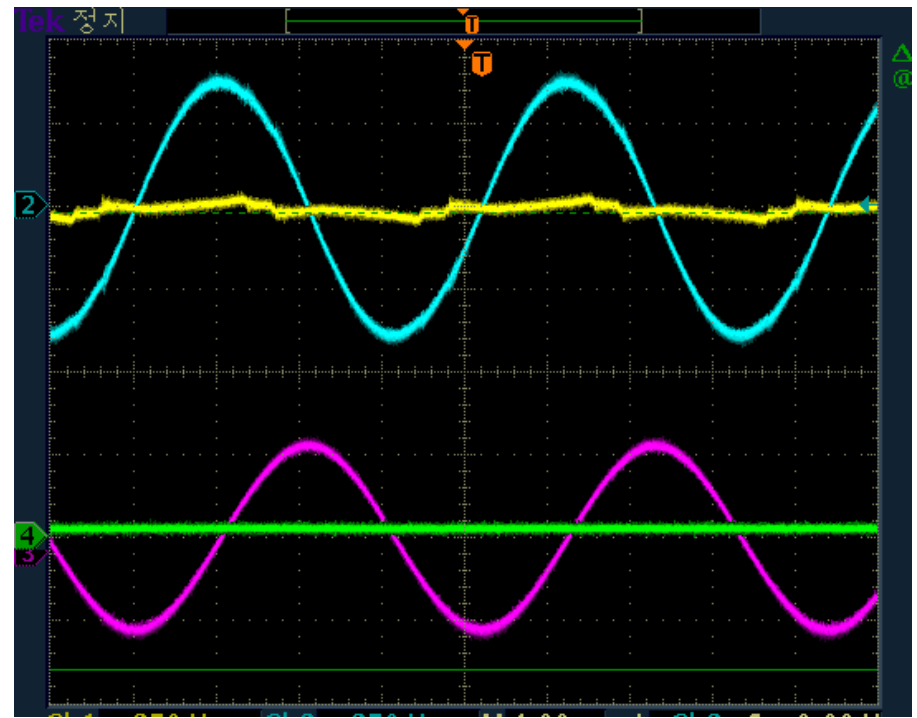

(b) $I_{2}=180 \mathrm{~A}_{\mathrm{rms}}$

Fig. 5: Short circuit test waveforms:

upper traces (yellow: terminal voltage of inverter, blue: secondary voltage) $250 \mathrm{~V} / \mathrm{div}$, lower traces (pink: inverter current, green: feeder current) 200A/div, time base: $4 \mu \mathrm{sec} / \mathrm{div}$. 


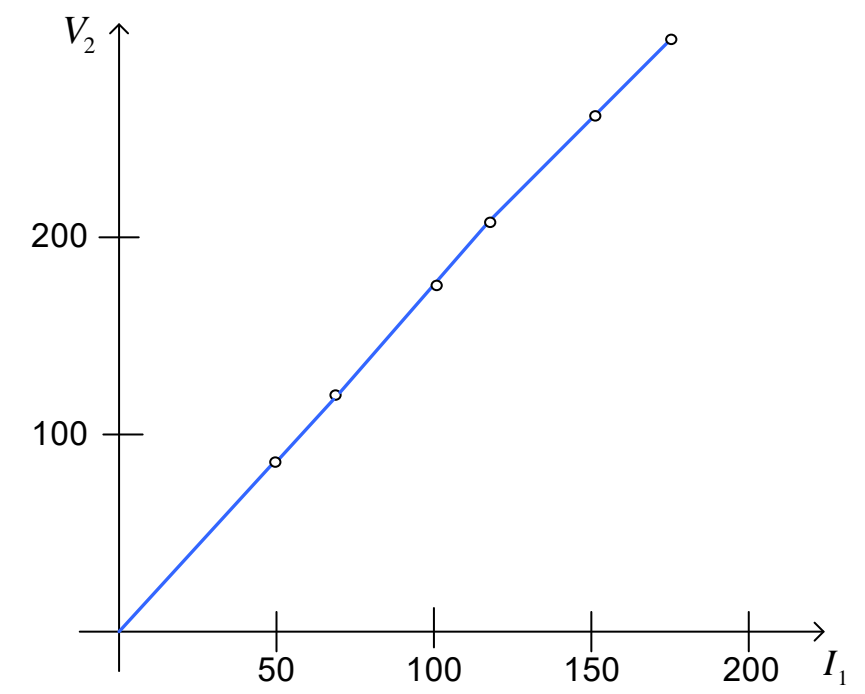

Fig. 6: The secondary voltage vs. the primary current at short-circuit test.

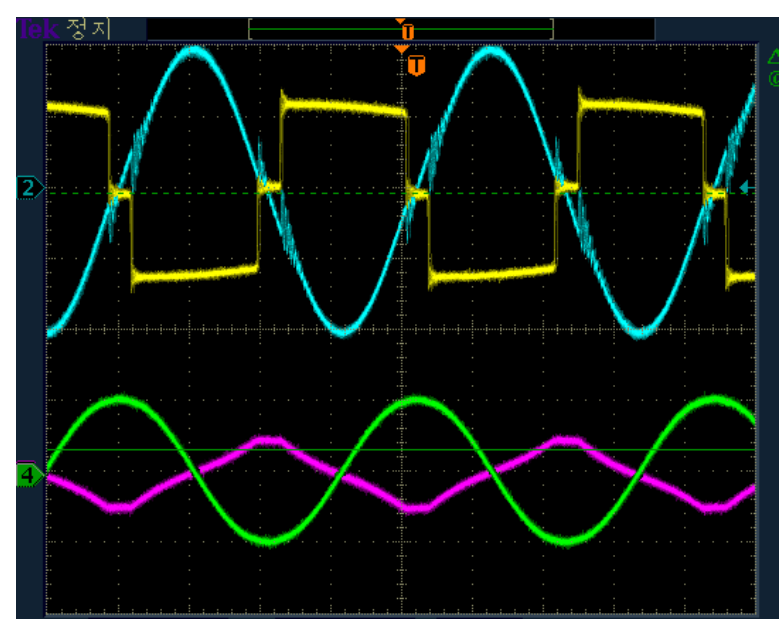

Fig. 7: Open circuit test waveforms: upper traces (yellow: terminal voltage of inverter 250V/div, blue: pickup voltage 250V/div) lower traces (pink: inverter current, green: feeder current) 200A/div, time base: $4 \mu \mathrm{sec} / \mathrm{div}$.

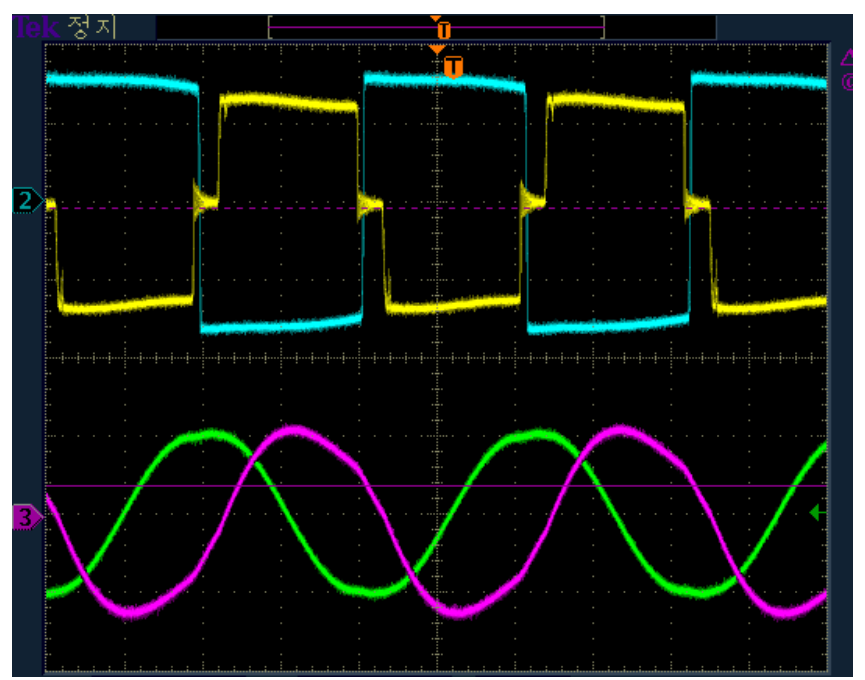

Fig. 8: Load (40kW) test waveforms: upper traces (yellow: terminal voltage of inverter 250V/div, blue: pickup voltage 250V/div) lower traces (pink: inverter current, green: feeder current) 200A/div, time base: $4 \mu \mathrm{sec} / \mathrm{div}$. 


\section{Conclusion}

In this paper, a resonant converter with fully-compensated isolation transformer suitable for wireless power transfer systems is proposed. Very attractive feature which facilitates a control of feeder current is obtained. A prototype resonant converter of $60 \mathrm{~kW}$ for wireless charging of electric YTs was made and tested. SiC FETs were used for switching devices and its circuit topology and control scheme were much simplified. Its experimental results show the validity of the proposal and the analysis.

\section{References}

[1] K. Hatanaka, F. Sato, H. Matsuki, S. Kikuchi, J. Murakami, M. Kawase and Satoh, "Power transmission of a desk with a cord-free power supply," IEEE Trans. Magnetics, vol. 38, no. 5, pp. 3329-3331, 2002.

[2] A. Kurs, A. Karalis, R. Moffatt, J. D. Joannopoulos, P. Fisher and M. Soljacic, "Wireless Power Transfer via strongly coupled magnetic resonances," Science, vol. 317, no. 83, pp.83-86, 2007.

[3] Y. S. Seo, Z. Hughes, M. Hoang, and D. Isom, "Investigation of wireless power transfer in through wall applications," in Proceedings of APMC 2012, 2012, pp.403-405.

[4] J. Wang, S.L. Ho, W.N. Fu, and M. Sun, "Analytical design of a novel witricity charger with lateral and angular misalignments for efficient wireless energy transmission," IEEE Trans. Magnetics, vol. 47, no. 10, pp. 2616-2619, 2011.

[5] S.G. Lee, H. Haong, Y. H. Choi and F. Bien, "Efficiency improvement for magnetic resonance based wireless power transfer with axial-misalignment," Electronics Letters, vol. 48, no. 6, pp. 339-340, 2012.

[6] D.-N. Lim, D.-S. Lee and S.-J. Jeon, "Wireless power transfer system insensitive to pickup's posture," in Proceedings of 43rd KIEE Summer Conference, 2012, pp. 1171-1172.

[7] O. Jonah, S.V. Georgakopoulos and M.M. Tentzeris, "Orientation insensitive power transfer by magnetic resonance for mobile device," in Proceedings of 2013 IEEE Wireless power Transfer Conference, 2013, pp. 5-8.

[8] D.H. Freeman and G.A. Freeman, "Wearable device with flexible display," US patent 593764A, 1999.

[9] M. DiRienzo, F. Rizzo, G. Parati, et al., "MagIC system: a new-textile-based wearable device for biological signal monitoring. Applicability in daily life and clinic setting," in Proceedings of PIEEE-EMBS 2005, 2005, pp. 7167-7169.

[10] D.-N. Lim, D.-S. Lee, S.-J. Jeon, and K. S. Lee, "Wireless power transfer system Suitable for Wristwatch Type Equipment," in Proceedings of IEEE WPTC 2014, pp. 141-177.

[11] J. Shin, S. Shin, Y. Kim, S. Ahn, S. Lee, G. Jung, S.-J. Jeon and D.-H. Cho, "Design and implementation of shaped magnetic-reonance-based wireless power transfer system for roadway powered moving electric vehicle," IEEE Trans. Ind. Electronics, vol. 61, no. 2, pp. 1179-1192, 2014.

[12] J. Boys, "Inductive power transfer across an extended gap," WO 98/50993, 1998.

[13] C.-S. Wang, O. H. Stielau and G. A. Covic, "Design considerations for a contactless electric vehicle battery charger," IEEE trans. Ind. Elec. vol. 52, no. 5, pp. 1308-1314, 2005.

[14] J. Heo, D.-S. Lee, S.-J. Jeon, and N. H. Kim, "Furtive Charging System for Electric Yard Tractor," in Proceedings of IEEE ITEC 2016, 2016, pp. 712-716.

[15] ICNIRP, "ICNIRP guidelines for limiting exposure to time-varying electric and magnetic fields (1 Hz to $100 \mathrm{kHz}$ )," Health Physics, vol. 99, no. 6, pp. 818-836, 2010.

[16] R. L. Steigerwald, "A comparison half-bridge resonant converter topologies," IEEE Trans. Power Electronics, vol. 3, no. 2, pp.174-182, 1998.

[17] M. Rashid, Power Electronics, Englewood Cliffs, NJ: Prentice Hall, 1993. 